\title{
Constitutively Active TRPC3 Channels Regulate Basal Ganglia Output Neurons
}

\author{
Fu-Wen Zhou, Shannon G. Matta, and Fu-Ming Zhou \\ Department of Pharmacology, University of Tennessee College of Medicine, Memphis, Tennessee 38163
}

\begin{abstract}
A hallmark of the GABA projection neurons of the substantia nigra pars reticulata ( $\mathrm{SNr}$ ), a key basal ganglia output nucleus, is its depolarized membrane potential and rapid spontaneous spikes that encode the basal ganglia output. Parkinsonian movement disorders are often associated with abnormalities in SNr GABA neuron firing intensity and/or pattern. A fundamental question remains regarding the molecular identity of the ion channels that drive these neurons to a depolarized membrane potential. We show here that SNr GABA projection neurons selectively express type 3 canonical transient receptor potential (TRPC3) channels. These channels are tonically active and mediate an inward, $\mathrm{Na}^{+}$-dependent current, leading to a substantial depolarization in these neurons. Inhibition of TRPC 3 channels induces hyperpolarization, decreases firing frequency, and increases firing irregularity. These data demonstrate that TRPC 3 channels play important roles in ensuring the appropriate firing intensity and pattern in $\mathrm{SNr}$ GABA projection neurons that are crucial to movement control.
\end{abstract}

Key words: basal ganglia; firing pattern; Parkinson's disease; single cell RT-PCR; substantia nigra pars reticulata; TRPC3 channel

\section{Introduction}

Substantia nigra pars reticulata $(\mathrm{SNr})$ is a key output nucleus of the basal ganglia (DeLong, 1990; Hikosaka et al., 2000; Parent et al., 2000; Cebrian et al., 2005). Its GABA projection neurons fire high-frequency spontaneous spikes that encode the basal ganglia output (Hikosaka and Wurtz, 1983; Schultz, 1986; Wichmann et al., 1999; Gulley et al., 2002; Sato and Hikosaka, 2002; Maurice et al., 2003; Atherton and Bevan, 2005). The rapid tonic activity of these GABA neurons ensures that their targets such as thalamus and brainstem motor nuclei are under a constant inhibitory control (Deniau et al., 2007; Hikosaka, 2007). The activity of basal ganglia output neurons [SNr GABA neurons and the GABA neurons of the internal segment of globus pallidus (GPi)] plays critical roles in movement control. Parkinsonian movement disorders are often associated with alterations in the firing rate and/or firing patterns of these basal ganglia output neurons (Nevet et al., 2004; Tang et al., 2005; Rivlin-Etzion et al., 2006; Wichmann and Soares, 2006; Lee et al., 2007).

A fundamental question is: what ion channels tonically depolarize these SNr GABA projection neurons and consequently enable these neurons to fire spontaneously? The persistent, voltagegated, tetrodotoxin (TTX)-sensitive $\mathrm{Na}^{+}$channel is involved, but not sufficient, because the membrane potential is about $-50 \mathrm{mV}$ after blocking the $\mathrm{Na}^{+}$channels with TTX (Atherton and Bevan,

Received Aug. 30, 2007; revised Nov. 26, 2007; accepted Nov. 27, 2007.

This work was supported by grants from the American Parkinson Disease Association, the National Alliance for Research on Schizophrenia and Depression, National Institute on Drug Abuse Grant R01DA021194, and National Institute of Mental Health Grant R01MH067119 to F.M.Z., and National Institute on Drug Abuse Grant R01 DA015525 to S.G.M. We thank Wenbo Ge for technical assistance and Dr. Suzhen Gong for help with confocal microscopy.

Correspondence should be addressed to Fu-Ming Zhou, Department of Pharmacology, University of Tennessee College of Medicine, Memphis, TN 38163.E-mail: fzhou3@utmem.edu.

DOI:10.1523/JNEUROSCI.3978-07.2008

Copyright $\odot 2008$ Society for Neuroscience $\quad$ 0270-6474/08/280473-10\$15.00/0
2005; Zhou et al., 2006). This membrane potential is considerably depolarized from the commonly encountered neuronal resting membrane potential of $-60 \mathrm{mV}$ to $-70 \mathrm{mV}$ that is often determined largely by background $\mathrm{K}^{+}$channels and the $\mathrm{Na}^{+} / \mathrm{K}^{+}$ pump (McCormick, 2004). Therefore, additional ion channels with suitable activation and inactivation properties are required to tonically depolarize SNr GABA neurons to around $-50 \mathrm{mV}$. Several members of the TRP channel family, TRPC3 channel in particular, are potential candidates because of their constitutive, voltage-independent activity (Albert et al., 2006).

TRP channels are a major class of recently discovered cation channels, with 28 members in mammalian animals (Clapham, 2003; Ramsey et al., 2006; Hardie, 2007; Nilius et al., 2007; Venkatachalam and Montell, 2007). They have diverse activation mechanisms including being constitutively active, chemosensitive, mechanosensitive, and thermosensitive. TRP channels are expressed in many types of tissues including the brain (Sylvester et al., 2001; Nilius et al., 2007). The functions of TRP channels in the brain are just beginning to be understood (Moran et al., 2004; Nilius et al., 2007). A recent study (Lee and Tepper, 2007) indicates that a TRP channel may underline a plateau potential in $\mathrm{SNr}$ GABA neurons.

We ask this question: can TRP channels provide a robust depolarizing drive to SNr GABA neurons? We hypothesize that one or multiple types of TRP channels with properties matching the functional needs of SNr GABA neurons are selectively expressed in these neurons. The constitutively active, voltage-independent TRP channel(s) such as the TRPC3 channel may thus substantially depolarize these neurons, particularly when their initial membrane potential is at hyperpolarized levels where other depolarizing channels are inactive. Consequently, TRP channels may play major roles in ensuring the depolarized membrane po- 
tential that enables the high firing frequency and regular firing pattern in these basal ganglia output neurons.

\section{Materials and Methods}

\section{Patch clamp in midbrain slices}

Wild-type 15- to 21-d-old male and female C57BL/6J mice were used. Mice were kept at the animal facility of the University of Tennessee Health Science Center in Memphis. Animal handling and use followed National Institutes of Health guidelines. Under deep urethane anesthesia, animals were transcardially perfused with oxygenated ice-cold highsucrose cutting solution (see below, Composition of solutions) under 40 $\mathrm{cm} \mathrm{H}_{2} \mathrm{O}$ pressure at the flow rate of $2 \mathrm{ml} / \mathrm{min}$. Then the mice were decapitated and their brains were quickly dissected out, and immersed in the ice-cold oxygenated cutting solution for $2.0 \mathrm{~min}$. Coronal midbrain slices (300 $\mu \mathrm{m}$ thickness) containing the midrostral part of substantia nigra were prepared in ice-cold oxygenated high-sucrose cutting solution using a Vibratome 1000 Plus (Vibratome, St. Louis, MO). Coronal sections were chosen to maximally sever afferent fibers such that $\mathrm{SNr}$ neurons can be studied in relative isolation. The slices were then transferred to a storage chamber containing oxygenated normal extracellular solution (see Composition of solutions) at room temperature $\left(\sim 23^{\circ} \mathrm{C}\right)$ for at least $1 \mathrm{~h}$ before transferring to a recording chamber. Recordings were made at $30^{\circ} \mathrm{C}$ under visual guidance of a video microscope (BX51WI; Olympus, Tokyo, Japan) equipped with Nomarski optics and $60 \times$ waterimmersion lens.

Conventional whole-cell patch-clamp techniques were used (Zhou et al., 2006). Patch pipettes were pulled from borosilicate (KG-33) glass capillary tubing $(1.10 \mathrm{~mm}$ inner diameter, $1.65 \mathrm{~mm}$ outer diameter; Garner Glass, Claremont, CA) using a PC-10 puller (Narishige, Tokyo, Japan). Patch pipettes were filled with an internal solution containing (see Composition of solutions) and had resistances of 2-3 M $\Omega$ in the bath. A MultiClamp 700B amplifier, pClamp 9.2 software and Digidata $1322 \mathrm{~A}$ interface (Molecular Devices, Union City, CA) were used to acquire and analyze data. Signals were digitized at $5-20 \mathrm{KHz}$ and analyzed off-line. Recordings with access resistance increase of $>15 \%$ were rejected. Whole-cell conductance was monitored by a $100 \mathrm{~ms}$ voltage pulse of $10 \mathrm{mV}$ from holding potential $-70 \mathrm{mV}$. Voltage-current relationships were obtained by applying linear voltage ramp from -90 to $10 \mathrm{mV}$ at a rate of $200 \mathrm{mV} / \mathrm{s}$ every $1 \mathrm{~min}$. The voltage ramp protocol was executed with Clampex 9.2 and recorded with Axoscope 9 and MiniDigi 1A (Molecular Devices).

\section{Composition of solutions}

High sucrose cutting solution contained (in $\mathrm{mm}$ ) 220 sucrose, $2.5 \mathrm{KCl}$, $1.25 \mathrm{NaH}_{2} \mathrm{PO}_{4}, 25 \mathrm{NaHCO}_{3}, 0.5 \mathrm{CaCl}_{2}, 7 \mathrm{MgCl}_{2}$, and $10 \mathrm{D}$-glucose. Normal extracellular solution contained (in $\mathrm{mM}$ ) $125 \mathrm{NaCl}, 2.5 \mathrm{KCl}, 1.25$ $\mathrm{NaH}_{2} \mathrm{PO}_{4}, 25 \mathrm{NaHCO}_{3}, 2.5 \mathrm{CaCl}_{2}, 1.3 \mathrm{MgCl}_{2}, 10$ D-glucose, maintaining $\mathrm{pH}$ at 7.4 by continuously bubbling with $95 \% \mathrm{O}_{2}$ and $5 \% \mathrm{CO}_{2}$. The total $\mathrm{Na}^{+}$concentration was $151.25 \mathrm{~mm}$. Normal intracellular solution contained (in mM) $135 \mathrm{KCl}$, 0.5 EGTA, 10 HEPES, 2 Mg-ATP, 0.2 Na-GTP, and 4 Na-phosphocreatine. $\mathrm{pH}$ was adjusted to 7.25 with $\mathrm{KOH}$. The observed responses using this high chloride internal were comparable to those with $125 \mathrm{~mm} \mathrm{~K}$-gluconate and $10 \mathrm{~mm} \mathrm{KCl-based} \mathrm{intracellular}$ solution.

Low $\mathrm{Na}^{+}$extracellular solution contained (in mM) 125 choline chloride, $2.5 \mathrm{KCl}, 1.25 \mathrm{NaH}_{2} \mathrm{PO}_{4}, 25 \mathrm{NaHCO}_{3}, 2.5 \mathrm{CaCl}_{2}, 1.3 \mathrm{MgCl}_{2}$, and 10 D-glucose. Extracellular sodium concentration was reduced to $26.25 \mathrm{mM}$ from 151.25 by substituting $\mathrm{NaCl}$ with equal molar amounts of choline chloride.

When $\mathrm{GdCl}_{3}$ was used, the extracellular solution contained (in $\mathrm{mM}$ ) 151.25 NaCl, $2.5 \mathrm{KCl}, 11 \mathrm{HEPES}, 2.5 \mathrm{CaCl}_{2}, 1.3 \mathrm{MgCl}_{2}, 10 \mathrm{D}$-glucose, and 18 sucrose. $\mathrm{NaHCO}_{3}$ and $\mathrm{NaH}_{2} \mathrm{PO}_{4}$ were not used to avoid precipitation. $\mathrm{Na}^{+}$concentration was kept constant by using $\mathrm{NaCl}$. Osmolarity was kept constant by adding sucrose.

\section{Single-cell reverse-transcription PCR}

Single-cell reverse-transcription PCR (scRT-PCR) procedures generally followed the well established principles and methods (Surmeier et al., 1996; Liss and Roeper, 2004). Patch pipettes were autoclaved to inacti- vate RNase. Intracellular solution [containing (in $\mathrm{mM}$ ) $135 \mathrm{KCl}, 0.5$ EGTA, 10 HEPES, and $1.5 \mathrm{MgCl}_{2}, \mathrm{pH}$ adjusted to 7.3 ] was prepared using DNase-RNase-free water. Brief ( $\sim 2 \mathrm{~min})$ recording was limited to providing electrophysiological fingerprints for SNr GABA and DA neurons. Once obtaining a stable recording, gentle suction was applied to aspirate the cytoplasm. The nucleus was likely to be also aspirated, leading to the necessity to digest genomic DNA. Complete removal of genomic DNA was verified by RT minus control in which no expected amplicon was detected when the reverse transcriptase was omitted whereas all other reaction components were exactly the same.

To rule out contamination of extracellular debris that may contain mRNAs, the patch pipette was lowered into the tissue without actually aspirating cytoplasm and then the pipette content was subjected to RTPCR, yielding no product at all.

Reverse transcription. The aspirated cell content was expelled into a $0.2 \mathrm{ml}$ PCR tube. Genomic DNA was digested by DNase I ( 5 min at $25^{\circ} \mathrm{C}$ ). cDNA was synthesized using SuperScript III reverse transcriptase-based Cells-Direct cDNA Synthesis kit (Invitrogen, Eugene, OR) designed for high specificity and high yield cDNA synthesis from small amounts of starting material without the need to isolate RNA. The kit also contained RNase inhibitor. According to manufacturer's instruction, RT was performed at $50^{\circ} \mathrm{C}$ for $50 \mathrm{~min}$, yielding $30 \mu \mathrm{l}$ of cDNA solution. The reaction was terminated by heating to $85^{\circ} \mathrm{C}$ for $5 \mathrm{~min}$ and then chilled on ice. The $30 \mu \mathrm{l}$ of cDNA solution was used either immediately for PCR amplification or stored at $-20^{\circ} \mathrm{C}$ for later use.

Two-stage PCR amplification. Using an Eppendorf (Hamburg, Germany) Mastercycler thermocycler, the cDNAs were amplified using a hot start, high specificity and high-yield Platinum PCR SuperMix (Invitrogen) that contained all necessary components in one tube. To maximize the detection probability of mRNAs in a single neuron, the so called two stage, nested PCR procedure was used (Surmeier et al., 1996; Liss and Roeper, 2004). In the first stage, $10 \mu \mathrm{l}$ of the $30 \mu \mathrm{l}$ cDNAs was amplified for 35 cycles in the presence of glutamic acid decarboxylase 1 (GAD1) outer primer pair (supplemental Table 1, available at www.jneurosci.org as supplemental material). The thermal cycling protocol was $2 \mathrm{~min}$ at $94^{\circ} \mathrm{C}$ for the initial denaturation, then 35 cycles of $15 \mathrm{~s}$ at $94^{\circ} \mathrm{C}$ to denature, $30 \mathrm{~s}$ at $55^{\circ} \mathrm{C}$ to anneal, and $45 \mathrm{~s}$ at $72^{\circ} \mathrm{C}$ to extend, followed by $7 \mathrm{~min}$ for a final extension. In the second stage PCR, the product of $1 \mu \mathrm{l}$ from the first stage PCR amplification was used as template and an inner primer pair was also used (supplemental Table 1). The inner primer pairs span shorter segments than the outer primer pair. Forty cycles were run with the extension time shortened to $30 \mathrm{~s}$.

After GAD1 mRNA detection that confirmed the GABA identity of the cell and the success of cytoplasm aspiration and cDNA synthesis, $10 \mu \mathrm{l}$ of the remaining cDNAs from the original $30 \mu \mathrm{l}$ of cDNAs was subjected to the same two-stage PCR amplification in the presence of appropriate outer and inner primer pairs for one of the following: TRPC1-7, TRPV1-6, TRPM1-8, TRPML1-3, TRPP2,3,5, and TRPA1 (supplemental Table 1, available at www.jneurosci.org as supplemental material).

PCR products from the second stage amplification were separated by $2.5 \%$ agarose gel electrophoresis, visualized by ethidium bromide $(0.05$ $\mathrm{mg} / 100 \mathrm{ml}$ gel) under UV light, and photographed. The positive bands were then cut out, went through a gel extraction procedure using a Qiagen (Hilden, Germany) extraction kit. The extraction products were sequenced at the Molecular Resource Center of University of Tennessee Health Science Center in Memphis, Tennessee.

PCR primer pairs for GAD1, tyrosine hydroxylase (TH), and the 28 TRP channels were designed based on the sequences from GenBank and listed in supplemental Table 1 (available at www.jneurosci.org as supplemental material). Designing was accomplished using the web-based Primer3 software (http://fokker.wi.mit.edu/primer3/input.htm) (Massachusetts Institute of Technology, Cambridge, MA). Whenever possible, intron-spanning primer pairs were used that help detect genomic DNA contamination. All primers were synthesized by Integrated DNA Technologies (Coralville, IA; www.idtdna.com).

To prevent or minimize false negative single cell RT-PCR detection caused by ineffective primers, all outer and inner primer pairs for GAD1, $\mathrm{TH}$, and the $28 \mathrm{TRP}$ mRNAs were confirmed to be effective with whole brain mRNAs. In this procedure, a Promega RNA isolation kit was used 
A

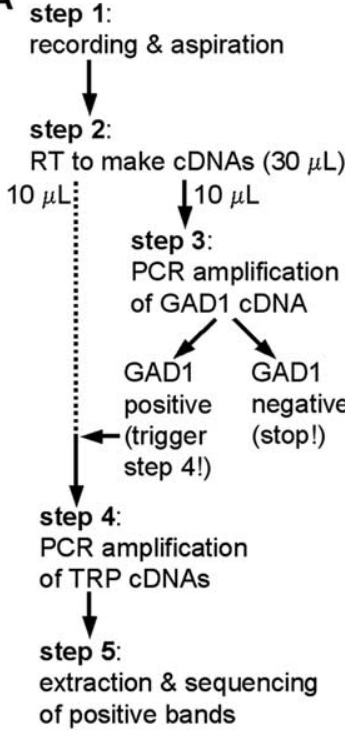

\section{B GAD1 mRNA-positive SNr neurons}

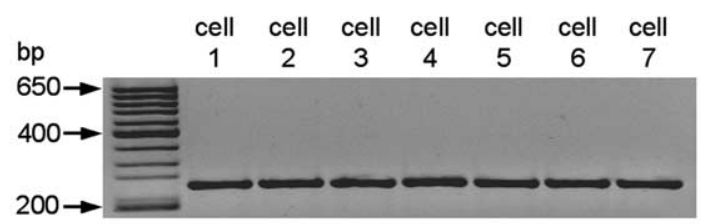

C Only TRPC3 mRNA was detected in GAD1 mRNA-positive $\mathrm{SNr}$ neurons

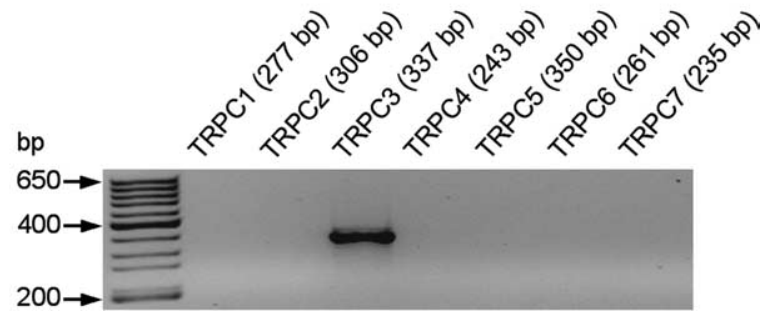

Figure 1. $\quad s c R T-P C R$ reveals selective expression of TRPC3 mRNA in SNr GABA neurons. $A$, Simplified protocol illustrating the steps of our scRT-PCR. Note that successful PCR amplification was conditioned on successful aspiration and RT. GAD1 mRNA was not detected in a minority of electrophysiologically identified GABA neurons, indicating a likely failure in aspiration. $B, G A D 1$ mRNA (expected amplicon size 244 bp) was consistently detected in electrophysiologically identified SNr GABA neurons (114 of 123). Detection of GAD1 mRNA indicates that a sufficient amount of cytoplasm was aspirated and cellular mRNAs were sufficiently preserved, creating the precondition to detect other mRNAs. $C$, In the electrophysiologically identified SNr GABA neurons in which GAD1 mRNA was detected, scRT-PCR reliably detected TRPC3 mRNA ( $n=10$ of 10 ) whereas TRPC $1,2,4,5,6,7$ mRNAs were not detected. Primer pairs were effective (supplemental Fig. 1, supplemental Table 1, available at www.jneurosci.org as supplemental material).

to obtain the total RNA from one hemisphere of the brain (including the cerebellum) of a 16-d-old mouse. The resultant RNA was reversed transcribed into cDNA using the same RT kit used in single cell RT-PCR. The cDNA was subjected to PCR amplification using the primer pairs that were used in single cell RT-PCR. All these primer pairs yielded amplicons of expected sizes (supplemental Fig. 1, available at www.jneurosci.org as supplemental material). These positive control results indicate that the primer pairs used in our single cell RT-PCR were effective and that the negative detection was caused by a lack or undetectable level of expression.

\section{Immunohistochemistry}

Under lethal Nembutal anesthesia, mice were intracardially perfused with the ice-cold cutting solution described above and then $4 \%$ paraformaldehyde in 0.1 m PBS. The removed brains were infused with $30 \%$ sucrose $/ 0.1$ phosphate buffer $/ 0.1 \%$ sodium Azide at $4^{\circ} \mathrm{C}$ overnight. Coronal midbrain sections ( $50 \mu \mathrm{m}$ thickness) were cut on a Vibratome 1000 Plus. The sections were processed for immunofluorescence detection of parvalbumin (PV) and TRPC3. Briefly, after incubation with $10 \%$ methanol and $3 \% \mathrm{H}_{2} \mathrm{O}_{2}$ in $0.01 \mathrm{M}$ PBS for $5 \mathrm{~min}$ at room temperature to quench endogenous peroxidase. Then the sections were incubated with $1 \%$ normal donkey serum (NDS) and $1 \%$ normal goat serum (NGS), and $1 \%$ bovine serum albumin (BSA) and 1\% Triton- 100 in 0.01 м PBS for 30 min at room temperature to block nonspecific binding and permeate cell membrane. After thorough rinsing, the sections were incubated with the mixture of two primary antibodies and two secondary antibodies in $1 \%$ NDS and $1 \%$ NGS and $1 \%$ BSA plus $1 \%$ Triton- 100 in $0.01 \mathrm{~m} \mathrm{PBS} \mathrm{for} 48 \mathrm{~h}$ at $4^{\circ} \mathrm{C}$ in dark. The two primary antibodies were a mouse TRPC 3 antibody raised in rabbit (diluted at 1:400; Alomone Labs, Jerusalem, Israel) and monoclonal PV antibody raised in mouse (Sigma, St. Louis, MO; diluted at 1:1000). The two secondary antibodies were (1) anti-rabbit IgG antibody raised in goat, conjugated with red Alexa Fluor 568 (Invitrogen) diluted at 1:200, and used for labeling TRPC3 channel protein, and (2) an anti-mouse IgG antibody raised in donkey, conjugated with blue fluorescent Alexa Fluor 488, diluted at 1:200, and used for labeling PV.

To confirm the effective infusion of TRPC3 antibody via the patch pipette into the recorded SNr GABA neurons, we did the following: the intracellular solution was supplemented with the mouse TRPC3 antibody diluted at 1:100; after 3 min whole-cell recording, the slices were fixed in $4 \%$ paraformaldehyde in $0.1 \mathrm{M}$ PBS and further processed for double immunofluorescence labeling for TRPC3 antibody and parvalbumin using the same procedures described above.

\section{Chemicals}

Routine chemicals including D-2-amino-5phosphonopentanoic acid, 6-cyano-7nitroquinoxaline-2,3-dione, and picrotoxin were purchased from Sigma or Tocris (Ellisville, MO). Suppliers of molecular biology reagents were described individually in the text.

\section{Statistical analysis}

All values are expressed as mean \pm SEM. Student's paired $t$ test was used to compare results before and after drug administration with each neuron serving as its own control and the $p$ values are listed in the text without listing the test name. One-way ANOVA was used to compare results from different groups with both the $p$ values and test name listed together. $p<0.05$ was significant.

\section{Results \\ TRPC3 mRNA is selectively expressed in SNr GABA neurons}

To determine whether SNr GABA neurons express any TRP channels, we used the well established single cell RT-PCR (scRT-PCR) technique (Surmeier et al., 1996; Liss and Roeper, 2004) to detect the mRNAs for these channels. After electrophysiologically identifying the SNr GABA neurons (Atherton and Bevan, 2005; Zhou et al., 2006; Lee and Tepper, 2007) (supplemental Fig. 2, available at www. jneurosci.org as supplemental material), the cytoplasm or intracellular content of the recorded neuron was aspirated and subjected to two-stage scRT-PCR to detect mRNAs for GAD1 (GABA synthesis enzyme), TH (a key enzyme in dopamine synthesis), and the 28 known mouse TRP channels (TRPC1-7, TRPV1-6, TRPM1-8, TRPML1-3, TRPP2,3,5, and TRPA1) (Fig. $1 A$ ). In cells showing characteristic SNr GABA neuron action potentials, scRT-PCR revealed GAD1 mRNA, but not $\mathrm{TH}$ mRNA, indicating that our electrophysiological identification of the SNr GABA neuron was reliable. More important, TRPC3 mRNA was consistently detected in these electrophysiologically identified, GAD1-positive SNr GABA neurons ( $n=10$ of 10 ) (Fig. $1 B, C$ ). No mRNA for the other 27 TRP channels was detected in similarly electrophysiologically identified, GAD1positive SNr GABA neurons $[n=3-5$ for each of these 27 different TRP channels (negative data not shown). PCR primer pairs were listed in supplemental Table 1 (available at www.jneurosci.org as supplemental material). The effectiveness of the primer pairs were positively confirmed with whole brain mRNA (supplemental Fig. 1, available at www.jneurosci.org as supplemental material)]. The PCR products or amplicons were sequenced and positively identified with GAD1 and TRPC3 mRNAs, respectively.

These results suggest that TRPC3 channel mRNA is selectively expressed in SNr GABA neurons whereas other TRP channel mRNAs are not expressed at detectable levels. Translation of TRPC3 mRNA into TRPC3 protein in SNr GABA neurons is 
confirmed by the widespread TRPC3 immunoreactivity in $\mathrm{PV}$-positive $\mathrm{SNr}$ neurons (Fig. 2). PV is a reliable marker for SNr GABA projection neurons whereas GABA synthesis enzyme GAD is not because of its low level at the soma (Rajakumar et al., 1994; Gonzalez-Hernandez and Rodriguez, 2000).

We will provide functional data below that TRPC3 mRNA is translated into functional channel proteins in SNr GABA neurons. In other cell systems, the TRPC3 channel is a constitutively active cation channel and plays major roles in determining cell resting membrane potential and action potential firing (Albert et al., 2006). Thus, we hypothesized that in $\mathrm{SNr}$ GABA neurons, TRPC3 channels may mediate a tonic inward current that contributes substantially to the depolarized membrane potential and high frequency firing in these basal ganglia output neurons.

TRP channel blockade reveals a tonic depolarization and inward current in SNr GABA neurons

To test our hypothesis, we used flufenamic acid (FFA), a broad spectrum TRP channel (including TRPC3 channel) blocker (Albert et al., 2006; Ramsey et al., 2006). If TRPC3 channels indeed conduct a tonic inward current in $\mathrm{SNr}$ GABA neurons, then FFA should induce an apparent hyperpolarization in current clamp and an apparent outward current in voltage clamp. In this experiment and all other experiments described below, $20 \mu \mathrm{M}$ D-2-amino-5-phosphonopentanoic acid, $10 \mu \mathrm{M}$ 6-cyano-7-nitroquinoxaline-2,3-dione, and $100 \mu \mathrm{M}$ picrotoxin were used to eliminate complications of fast glutamate and GABA synaptic activity. $1 \mu \mathrm{M}$ TTX was used to abolish action potentials. The persistent $\mathrm{Na}^{+}$channel should also be blocked by TTX (Atherton et al., 2005). Under these conditions, the resting membrane potential in SNr GABA neurons was $-50.1 \pm 0.8 \mathrm{mV}$ $(n=29)$. Bath application of $100 \mu \mathrm{M}$ FFA consistently resulted in a nondesensitizing hyperpolarization of $9.7 \pm 0.9 \mathrm{mV}$ from the resting membrane potential of $-49.8 \pm 1.8 \mathrm{mV}(n=10)$ (Fig. $3 A$, Table 1). The effect of FFA was reversible after wash. These results clearly indicate that there was a nearly $10 \mathrm{mV}$ tonic depolarization in SNr GABA neurons that was sensitive to FFA inhibition.

Similar results were obtained in voltage clamp recording mode. At holding potential $-70 \mathrm{mV}$, the control resting holding current was $-156.0 \pm 3.5 \mathrm{pA}(n=42)$. Bath application of 100 $\mu \mathrm{M}$ FFA induced an apparent outward current of $65.2 \pm 3.3 \mathrm{pA}$, or reduced the potential tonic inward current by $65.2 \pm 3.3 \mathrm{pA}$ $(n=14)$ (Fig. $3 B$, Table 1$)$. In other words, FFA inhibited a normally active inward current. Whole-cell conductance, monitored with $10 \mathrm{mV}$ voltage pulses, was also decreased from $5.59 \pm$ $0.53 \mathrm{nS}$ under control to $3.51 \pm 0.42 \mathrm{nS}$ during FFA application $(n=7 ; p<0.001)$. These results clearly indicate that SNr GABA neurons have a constitutively active inward current that is sensitive to FFA, a nonselective TRP channel blocker.

To determine the current-voltage $(I-V)$ relationship of the tonic inward current, voltage ramp experiments were performed. Linear voltage ramp between -90 to $10 \mathrm{mV}$ revealed that FFA decreased the whole cell current in the entire voltage range. The $I-V$ relationship of this FFA-inhibited inward current, obtained
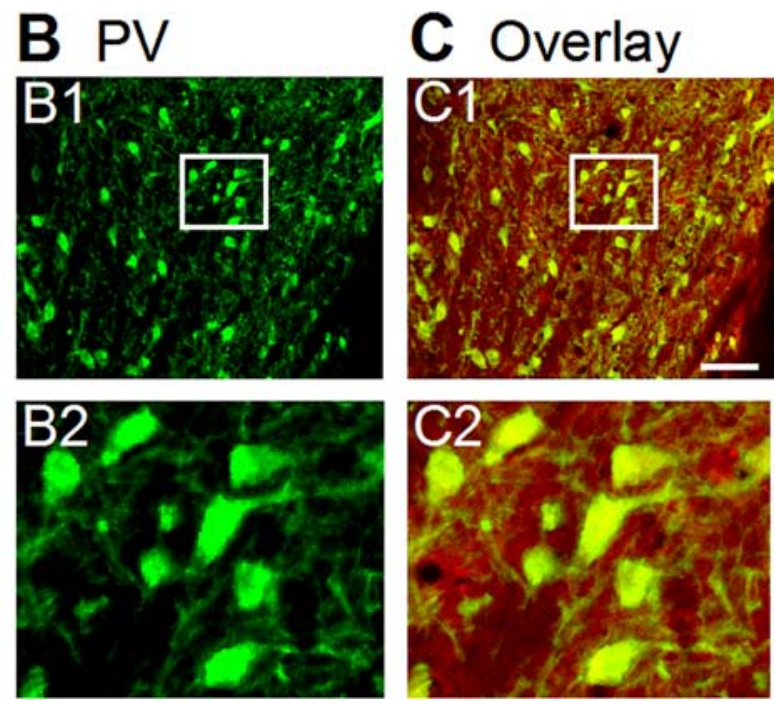

Figure 2. TRPC3 channel protein immunoreactivity in SNr GABA neurons. $\boldsymbol{A}, \boldsymbol{A} \boldsymbol{1}$ shows numerous TRPC3 immunoreactivityposed neurons in a $50 \mu \mathrm{m}$-thick SNr section. The boxed area is enlarged and shown in $\boldsymbol{A 2}$. The indicating a widespread expression of TRPC3 channel protein in SNr GABA neurons. All images were confocal photomicrographs.
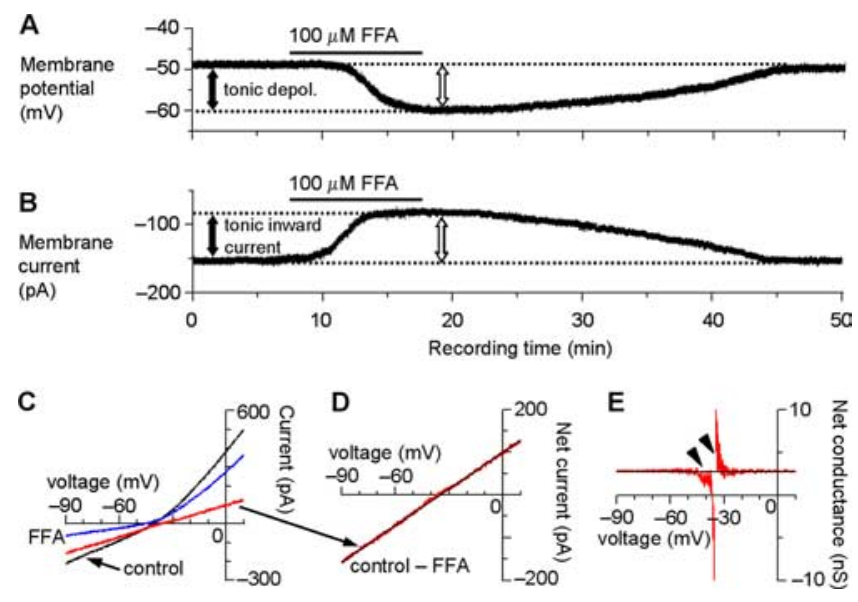

Figure 3. TRP channel blockade reveals a tonic depolarization and inward current in SNr GABA neurons. $A$, After blocking $\mathrm{Na}^{+}$channels with $1 \mu \mathrm{m}$ TTX and under current clamp recording condition, bath application of $100 \mu \mathrm{M}$ FFA, a broad-spectrum compound known to block TRP channels, resulted in an apparent hyperpolarization of $\sim 10 \mathrm{mV}$ from the resting membrane potential around $-50 \mathrm{mV}$ (open arrow), indicating an FFA-sensitive tonic depolarization (depol.; filled arrow). $\boldsymbol{B}$, When voltage clamped at $-70 \mathrm{mV}$, bath application of $100 \mu \mathrm{m}$ FFA induced an outward current of $\sim 65 \mathrm{pA}$ on average (open arrow), or reduced the potential tonic inward current by $\sim 65 \mathrm{pA}$ as reflected by the apparent reduction of the holding current (filled arrow). C, Linear voltage ramp from -90 to $10 \mathrm{mV}$ was applied under control condition (black trace) and during $100 \mu \mathrm{m}$ FFA application (blue trace). Digital subtraction (control minus FFA) revealed the current inhibited by FFA (red trace) and its I-V relationship. The decreased current also indicates an increased input resistance or decreased whole cell conductance. $\boldsymbol{D}$, The FFAinhibited current in $\boldsymbol{C}$ displayed at higher magnification. The $I-V$ relationship is clearly linear between the entire voltage range of -90 to $10 \mathrm{mV}$ with no signs of voltage-dependent activation or inactivation and reversed its polarity around $-36 \mathrm{mV}$ on average (intercept on $x$-axis in linear regression analysis as indicated by the black straight line, $r=0.999) . E$, The underlying FFA-sensitive conductance was flat with no voltage-dependent activation or inactivation. The portion near $-35 \mathrm{mV}$ was not reliable because when the driving force approached zero toward the reversal potential, the calculated conductance value (current divided by driving force) was highly affected by the noise current (arrowheads). When the driving force became zero at the reversal potential, the conductance became not defined as indicated by the gap (arrowheads). The black line was the linear fit $(r=0.998)$. 
Table 1. Bath-applied flufenamic acid and intracellularly applied TRPC3 antibody have similar effects on SNr GABA neurons

\begin{tabular}{|c|c|c|c|c|c|}
\hline & \multicolumn{3}{|l|}{ Steady state } & \multicolumn{2}{|c|}{$100 \mu \mathrm{m}$ FFA-induced } \\
\hline & $\begin{array}{l}\text { Firing rate } \\
(\mathrm{Hz})\end{array}$ & $\begin{array}{l}\text { Holding current } \\
\text { at }-70 \mathrm{mV}(\mathrm{pA})\end{array}$ & $\begin{array}{l}\text { Membrane } \\
\text { potential }(\mathrm{mV})\end{array}$ & $\begin{array}{l}\text { Outward } \\
\text { current }(\mathrm{pA})\end{array}$ & $\begin{array}{l}\text { Hyperpolarization } \\
(\mathrm{mV})\end{array}$ \\
\hline Control & $\begin{array}{l}10.4 \pm 0.2 \\
(n=123)\end{array}$ & $\begin{array}{c}-156.0 \pm 3.5 \\
(n=42)\end{array}$ & $\begin{array}{c}-50.1 \pm 0.8 \\
(n=29)\end{array}$ & $\begin{array}{c}-65.2 \pm 3.3 \\
(n=14)\end{array}$ & $\begin{array}{c}-9.7 \pm 0.9 \\
(n=10)\end{array}$ \\
\hline $100 \mu \mathrm{m} \mathrm{FFA}$ & $\begin{array}{c}0 \\
(n=7)\end{array}$ & $\begin{array}{c}-90.9 \pm 5.2 \\
(n=14)\end{array}$ & $\begin{array}{c}-59.5 \pm 1.1 \\
(n=10)\end{array}$ & not applicable & not applicable \\
\hline TRPC3 antibody & $\begin{array}{c}0 \\
(n=5)\end{array}$ & $\begin{array}{c}-95.1 \pm 10.4 \\
(n=6)\end{array}$ & $\begin{array}{c}-58.2 \pm 1.4 \\
(n=7)\end{array}$ & $\begin{array}{c}-11.8 \pm 0.7 \\
(n=6)\end{array}$ & $\begin{array}{c}-1.5 \pm 0.3 \\
(n=7)\end{array}$ \\
\hline TRPC3 antibody + peptide & $\begin{array}{c}10.1 \pm 0.9 \\
(n=5)\end{array}$ & $\begin{array}{c}-155.4 \pm 11.7 \\
(n=5)\end{array}$ & $\begin{array}{c}-49.8 \pm 1.2 \\
(n=5)\end{array}$ & $\begin{array}{c}-67.2 \pm 5.6 \\
(n=5)\end{array}$ & $\begin{array}{c}-9.5 \pm 1.1 \\
(n=5)\end{array}$ \\
\hline
\end{tabular}

by subtracting the ramp current under control by the ramp current in the presence of FFA, was linear between -90 and $10 \mathrm{mV}$ with no signs of voltage-dependent activation or inactivation. The current reversed its polarity at $-36.2 \pm 1.4 \mathrm{mV}(n=6)$ (Fig. $3 C, D)$. The underlying FFA-sensitive conductance was also flat with no voltage-dependent activation or inactivation (Fig. $3 E$ ). These $I-V$ characteristics and FFA-sensitivity indicate a potentially TRPC3 channel-mediated, tonic cation current in $\mathrm{SNr}$ GABA neurons. Because it is inward below the action potential threshold around $-40 \mathrm{mV}$, this tonic current can depolarize the cell toward spike firing.

To further characterize the ion channel mediating the tonic inward current in SNr GABA neurons, we tested the effects of $\mathrm{Gd}^{3+}$, a trivalent cation known to inhibit TRP channels, TRPC3 in particular (Albert et al., 2006; Ramsey et al., 2006). Bath application of $100 \mu \mathrm{M} \mathrm{GdCl}$ produced effects similar to those by 100 $\mu \mathrm{M}$ FFA on the membrane potential, current and whole-cell conductance. $\mathrm{Gd}^{3+}$ resulted in an apparent hyperpolarization of $9.5 \pm 0.8 \mathrm{mV}$ from $-50.3 \pm 2.0 \mathrm{mV}(n=6)$ (Fig. $4 A)$, an apparent outward current of $68.6 \pm 4.9 \mathrm{pA}$ or reduced the tonic inward current by $68.6 \pm 4.9 \mathrm{pA}(n=8)$ (Fig. $4 B)$. Whole-cell conductance was decreased from $5.83 \pm 0.72 \mathrm{nS}$ to $3.72 \pm 0.44 \mathrm{nS}$ $(n=6 ; p<0.001)$. Voltage ramp experiment revealed that the $\mathrm{Gd}^{3+}$-inhibited current was linear between -90 and $0 \mathrm{mV}$ with no signs of voltage-dependent activation or inactivation and reversed its polarity at $-34.7 \pm 1.5 \mathrm{mV}(n=5)$ (Fig. $4 C, D)$.

These results indicate that extracellular $\mathrm{Gd}^{3+}$ can inhibit the tonically active, voltage-independent inward current in $\mathrm{SNr}$ GABA neurons, consistent with our idea that TRPC3 channels may be mediating the tonic inward current and with published reports that native TRPC 3 channels are inhibited by extracellular gadolinium (Thorneloe and Nelson, 2004; Albert et al., 2006).

\section{The tonic depolarization and inward current in SNr GABA neurons are dependent on extracellular $\mathrm{Na}^{+}$}

The presence of TRPC3 mRNA, the absence of other TRP mRNAs, and the inward current's FFA-sensitivity and linearity all indicate that TRPC3 channels were probably mediating the tonic inward current in SNr GABA neurons. Because $\mathrm{Na}^{+}$is a main extracellular cation that is permeable to native TRP channels (Thorneloe and Nelson, 2004; Albert et al., 2006), we hypothesized that $\mathrm{Na}^{+}$is the main cation carrying the tonic inward current in SNr GABA neurons.

To test this idea, ion substitution experiments were performed. In current clamp recording mode and in normal bathing solution containing $151 \mathrm{mM} \mathrm{Na}^{+}$, and $1 \mu \mathrm{M}$ TTX, the resting membrane potential of SNr GABA neurons was around $-50 \mathrm{mV}$. When $125 \mathrm{~mm} \mathrm{NaCl}$ was replaced by equal molar choline chloride, a hyperpolarization of $10.8 \pm 1.4 \mathrm{mV}$ was induced from a
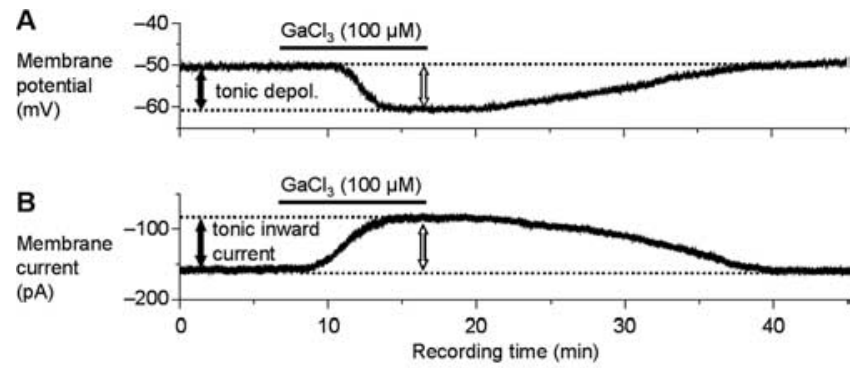

C
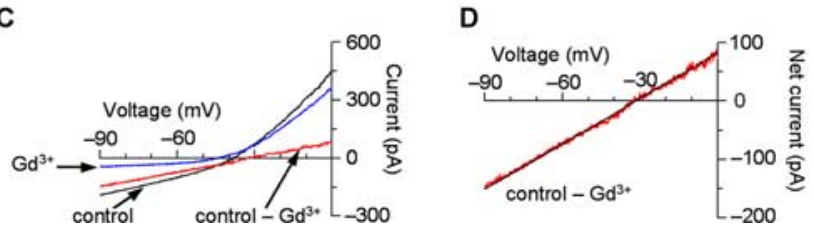

Figure 4. Extracellular $\mathrm{Gd}^{3+}$ inhibits the tonic depolarization (depol.) and inward current in SNrGABA neurons. $A$, In the presence of $1 \mu \mathrm{M}$ TTX and under current clamp recording condition, bath application of $100 \mu \mathrm{m} \mathrm{Gd}{ }^{3+}$ resulted in an apparent hyperpolarization of $\sim 10 \mathrm{mV}$ from the resting membrane potential near $-50 \mathrm{mV}$. The effect of $\mathrm{Gd}^{3+}$ was reversible after wash. $\boldsymbol{B}$, When voltage clamped at $-70 \mathrm{mV}$, bath application of $100 \mu \mathrm{m} \mathrm{Gd}{ }^{3+}$ induced an apparent outward current of $\sim 70 \mathrm{pA}$, or reduced the potential tonic inward current by $\sim 70 \mathrm{pA}$. In other words, $\mathrm{Gd}^{3+}$ inhibited a normally active inward current. $C$, Linear voltage ramp from -90 to 0 $\mathrm{mV}$ was applied under control condition (black trace) and during $100 \mu \mathrm{m} \mathrm{Gd}{ }^{3+}$ application (blue trace). Digital subtraction (control minus $\mathrm{Gd}^{3+}$ ) revealed the current inhibited by $\mathrm{Gd}^{3+}$ (red trace) and its $I-V$ relationship. The decreased current also indicates an increased input resistance or decreased whole-cell conductance. $\boldsymbol{D}$, The $\mathrm{Gd}^{3+}$-sensitive current in $\boldsymbol{C}$ displayed at higher magnification. The $I-V$ relationship is clearly linear between the entire voltage range of $-90 \mathrm{to} 0 \mathrm{mV}$ with no signs of voltage-dependent activation or inactivation and reversed its polarity around -34.7 on average (linear regression analysis as indicated by the black straight line, $r=0.998$ ).

baseline of $-50.2 \pm 2.1 \mathrm{mV}(n=7)$ (Fig. $5 A)$. Returning the bathing solution to normal extracellular solution reversed the hyperpolarization (Fig. 5A). In three additional cells, $1 \mu \mathrm{M}$ atropine and $2 \mu \mathrm{M}$ mecamylamine were present to prevent potential choline activation of muscarinic and nicotinic receptors and the results were not different. These data indicate that without the tonic $\mathrm{Na}^{+}$-dependent inward current, the resting membrane potential would be around $10 \mathrm{mV}$ more negative or around -60 $\mathrm{mV}$.

Similar results were obtained in voltage clamp recording mode. At holding potential $-70 \mathrm{mV}$, after obtaining stable baseline recording, replacing $125 \mathrm{~mm} \mathrm{NaCl}$ with equal molar choline chloride reduced the holding current by $73.9 \pm 3.8 \mathrm{pA}(n=11)$ (Fig. $5 B$ ), indicating a $\mathrm{Na}^{+}$-carried tonic inward current at -70 $\mathrm{mV}$. Comparison of linear voltage ramp-evoked current in normal Na${ }^{+}$and low $\mathrm{Na}^{+}$bathing solution revealed that the $\mathrm{Na}^{+}$dependent current was linear between -90 and $0 \mathrm{mV}$ and reversed its polarity at $-32.1 \pm 1.5 \mathrm{mV}(n=6)$ (Fig. $5 C, D)$. 


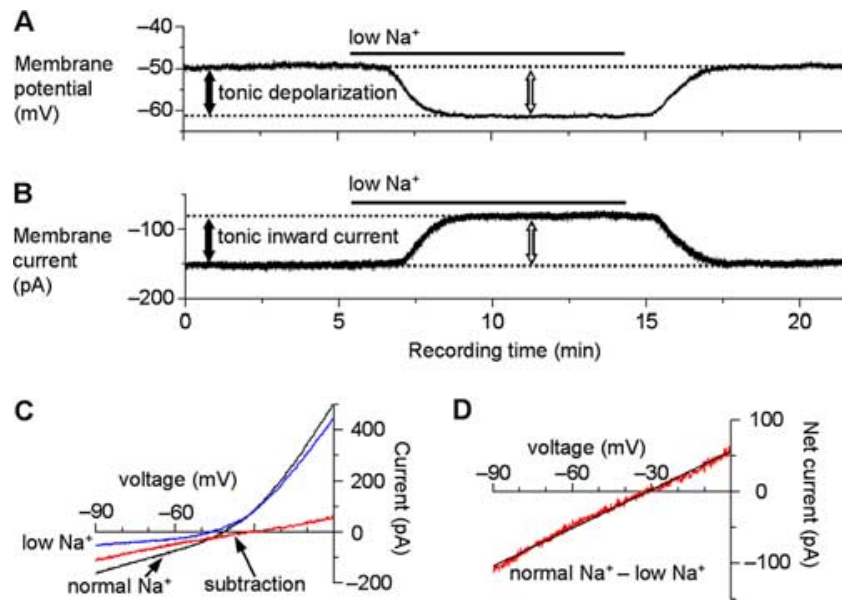

Figure 5. The tonic depolarization and inward current in $\mathrm{SNr}$ GABA neurons is dependent on extracellular $\mathrm{Na}^{+} . \boldsymbol{A}$, In current-clamp recording mode and in normal bathing solution containing $151.25 \mathrm{~mm} \mathrm{Na}^{+}$, the resting membrane potential of SNr GABA neurons was near $-50 \mathrm{mV}$ and very stable in the presence of $1 \mu \mathrm{m}$ TTX. When $125 \mathrm{~mm} \mathrm{NaCl}$ was replaced by equal molar choline chloride, a hyperpolarization of $\sim 10 \mathrm{mV}$ was induced (open arrow), indicating a $\mathrm{Na}^{+}$-dependent, tonic depolarization (filled arrow). Returning the bathing solution to normal extracellular solution reversed the hyperpolarization. $\boldsymbol{B}$, In voltage-clamp mode at holding potential $-70 \mathrm{mV}$, replacing $125 \mathrm{~mm} \mathrm{NaCl}$ in the bathing solution with equal molar choline chloride reduced the holding current by $\sim 70 \mathrm{pA}$ (open arrow), indicating a $\mathrm{Na}^{+}$-carried tonic inward current at $-70 \mathrm{mV}$ (filled arrow). C, Linear voltage ramp from -90 to $0 \mathrm{mV}$ was applied under normal $\mathrm{Na}^{+}$condition (black trace) and during low $\mathrm{Na}^{+}$condition (blue trace). Digital subtraction (normal $\mathrm{Na}^{+}$minus low $\mathrm{Na}^{+}$) revealed the current diminished by lowering $\mathrm{Na}^{+}$ (red trace) and its $I-V$ relationship. $\boldsymbol{D}$, The $\mathrm{Na}^{+}$-dependent current in $\boldsymbol{C}$ displayed at higher magnification. The $I-V$ relationship is clearly linear between the entire voltage range of -90 to $0 \mathrm{mV}$ with no signs of voltage-dependent activation or inactivation and reversed its polarity around $-32 \mathrm{mV}$ on average (intercept on $x$-axis in linear regression analysis as indicated by the black straight line, $r=0.997)$.

Furthermore, the effects of $100 \mu \mathrm{M}$ FFA on membrane potential and holding current was reduced by $82.8 \pm 3.6 \%$ and $84.7 \pm$ $3.8 \%(n=5)$, respectively, when extracellular $\mathrm{Na}^{+}$was reduced by $125 \mathrm{~mm}$ or $82.6 \%$ (Fig. 6), indicating that the FFA-sensitive tonic inward current was dependent on extracellular $\mathrm{Na}^{+}$. The effects of $100 \mu \mathrm{M} \mathrm{Gd}^{3+}$ on membrane potential and the tonic inward current were also reduced by $\sim 80 \%$ when extracellular $\mathrm{Na}^{+}$was reduced by $125 \mathrm{~mm}(n=3)$, indicating the $\mathrm{Gd}^{3+}$ sensitive tonic inward current was also dependent on $\mathrm{Na}^{+}$. These data further support our hypothesis that the tonic inward current was probably mediated by TRPC3 channels because $\mathrm{Na}^{+}$is known to carry the majority of the FFA- and $\mathrm{Gd}^{3+}$-sensitive, native TRPC3 channel-mediated current (Thorneloe and Nelson, 2004; Albert et al., 2006).

Together, these results suggest that SNr GABA neurons have a constitutively active, $\mathrm{Na}^{+}$-dependent, voltage-independent inward current at membrane potentials negative to the action potential threshold, indicating that this tonic inward current can depolarize and drive these neurons toward their action potential threshold. Given the selective presence of TRPC3 mRNA, the presence of TRPC 3 channel protein, and the FFA and $\mathrm{Gd}^{3+}$ sensitivity, these results suggest that TRPC 3 channels were the most likely candidate mediating this tonic inward current.

\section{Extracellular $\mathrm{Ca}^{2+}$ inhibits the tonic depolarization and inward current in SNr GABA neurons}

Extracellular $\mathrm{Ca}^{2+}$ is known to inhibit TRPC3 channel while enhancing the activity of other types of TRP channels (Thorneloe and Nelson, 2004; Albert et al., 2006). Our data presented above
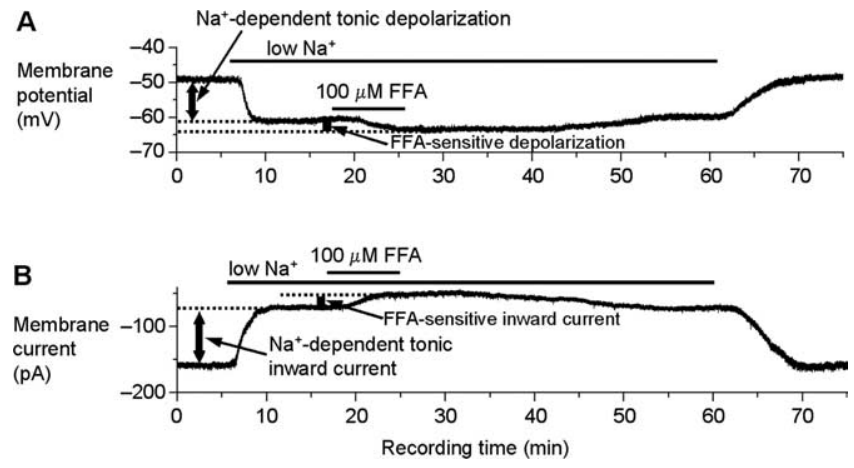

Figure 6. The effects of FFA are reduced when extracellular $\mathrm{Na}+$ concentration is reduced, indicating that the FFA-sensitive, tonic inward current in $\mathrm{SNr}$ GABA neurons is dependent on extracellular $\mathrm{Na}^{+} . \boldsymbol{A}$, In current-clamp recording mode and in normal bathing solution containing $151.25 \mathrm{~mm} \mathrm{Na}^{+}$, and $1 \mu \mathrm{M} \mathrm{TTX}$, the resting membrane potential of SNr GABA neurons was near $-50 \mathrm{mV}$ and stable. When $125 \mathrm{~mm} \mathrm{NaCl}$ was replaced by equal molar choline chloride, a hyperpolarization of $10.4 \pm 1.3 \mathrm{mV}$, from $-50.1 \pm 2.4 \mathrm{mV}$, was induced, indicating a $\mathrm{Na}^{+}$dependent tonic depolarization. Under this low $\mathrm{Na}^{+}$condition, $100 \mu \mathrm{m}$ FFA only induced a $1.6 \pm 0.3 \mathrm{mV}$ hyperpolarization $(n=5)$. It was $-9.7 \pm 0.9 \mathrm{mV}$ under normal $\mathrm{Na}^{+}$, indicating the FFA-sensitive tonic inward current was dependent on extracellular $\mathrm{Na}^{+}$. All these effects were recovered after washing out FFA and returning to normal $\mathrm{Na}^{+} . \boldsymbol{B}$, Similar results were obtained in voltage-clamp recording mode. At holding potential $-70 \mathrm{mV}$, replacing $125 \mathrm{~mm}$ $\mathrm{NaCl}$ in the bathing solution with choline chloride, on an equal molar base, reduced the holding current by $75.1 \pm 5.4 \mathrm{pA}$ from basal level of $-157.3 \pm 10.1 \mathrm{pA}$. Under this condition, $100 \mu \mathrm{M}$ FFA reduced the holding current by $-9.3 \pm 0.9 \mathrm{pA}(n=5)$. It was $-65.2 \pm 3.3 \mathrm{pA}$ under normal $\mathrm{Na}^{+}$.

indicate that TRPC3 channels may mediate the tonic inward current in SNr GABA neurons. Thus, we predicted that reducing extracellular $\mathrm{Ca}^{2+}$ concentration may enhance the tonic depolarization and inward current in SNr GABA neurons.

Indeed, after obtaining a stable baseline current clamp recording under the control condition with $2.5 \mathrm{mM} \mathrm{Ca}^{2+}$, reducing $\mathrm{Ca}^{2+}$ to $10 \mu \mathrm{M}$ resulted in a depolarization of $5.8 \pm 1.0 \mathrm{mV}$ from $-50.1 \pm 2.2 \mathrm{mV}(n=6)$ (Fig. $7 A)$. This effect was rapidly reversed with the reperfusion of normal bathing solution containing $2.5 \mathrm{mM} \mathrm{Ca}^{2+}$ (Fig. 7A). Similar results were obtained in voltage-clamp recording mode. At holding potential $-70 \mathrm{mV}$, reducing $\mathrm{Ca}^{2+}$ to $10 \mu \mathrm{M}$ from $2.5 \mathrm{~mm}$ increased the tonic inward current by $59.2 \pm 5.1 \mathrm{pA}$ by increasing the holding current to $-214.6 \pm 7.3 \mathrm{pA}$ from $-155.4 \pm 5.9 \mathrm{pA}$ under control condition with $2.5 \mathrm{mM} \mathrm{Ca}^{2+}(n=9)$ (Fig. $\left.7 B\right)$. Whole-cell conductance was also significantly increased from $5.32 \pm 0.57 \mathrm{nS}$ under control to $7.09 \pm 0.83 \mathrm{nS}(n=7 ; p<0.001)$ under $10 \mu \mathrm{M} \mathrm{Ca}^{2+}$. Voltage ramp experiments revealed that the inward current induced by reducing $\mathrm{Ca}^{2+}$ was linear between -90 and $0 \mathrm{mV}$ and reversed its polarity at $-37.2 \pm 1.7 \mathrm{mV}(n=6)$ (Fig. $7 C, D)$. These results indicate that extracellular $\mathrm{Ca}^{2+}$ normally inhibits a tonically active, voltage-independent inward current in SNr GABA neurons. This $\mathrm{Ca}^{2+}$ sensitivity is similar to that of the native TRPC3 channels in smooth muscle cells that are inhibited by extracellular calcium (Thorneloe and Nelson, 2004; Albert et al., 2006).

\section{Intracellular perfusion of TRPC3 antibody inhibits the tonic} depolarization and inward current in $\mathrm{SNr}$ GABA neurons The presence of TRPC3 mRNA and protein, lack of mRNA for other TRP channels, and the biophysical and pharmacological data presented above clearly indicate that the tonic, voltageindependent inward current in SNr GABA neurons is likely mediated by TRPC3 channels. However, FFA and $\mathrm{Gd}^{3+}$ may also affect other targets such as $\mathrm{Ca}^{2+}$ channels and NMDA-type glu- 


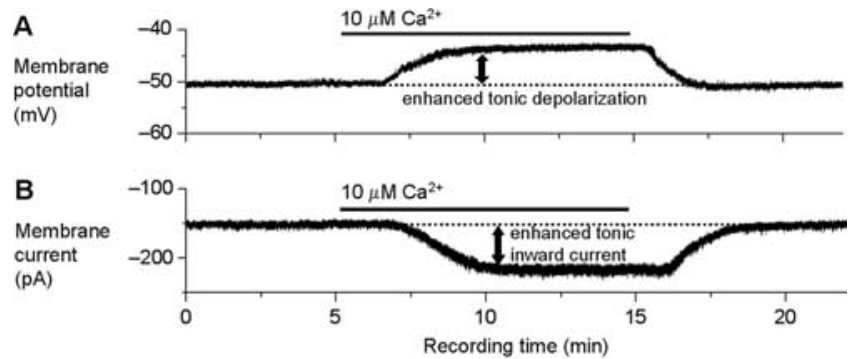

C

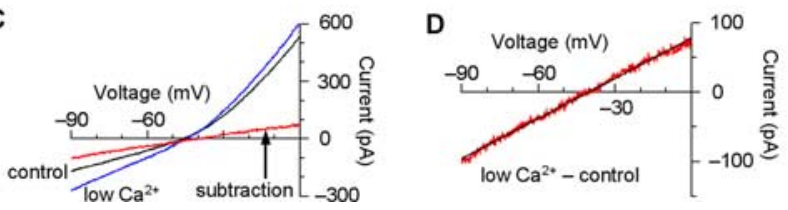

Figure 7. Extracellular $\mathrm{Ca}^{2+}$ inhibits the tonic depolarization and inward current in $\mathrm{SNr}$ GABA neurons. $A$, Under the current-clamp recording condition, reducing extracellular $\mathrm{Ca}^{2+}$ to $10 \mu \mathrm{m}$ from $2.5 \mathrm{~mm}$ resulted in a depolarization of $\sim 6 \mathrm{mV}$ from the resting membrane potential around $-50 \mathrm{mV}$. The effect of $\mathrm{Ca}^{2+}$ was reversible after return to normal $2.5 \mathrm{~mm} \mathrm{Ca}^{2+} . \boldsymbol{B}$, When voltage clamped at $-70 \mathrm{mV}$, reducing extracellular $\mathrm{Ca}^{2+}$ to $10 \mu \mathrm{m}$ induced an inward current of $\sim 60 \mathrm{pA}$, or enhanced the tonic inward current by $\sim 60 \mathrm{pA}$. In other words, $\mathrm{Ca}^{2+}$ inhibited a normally active inward current. C, Linear voltage ramp from -90 to $0 \mathrm{mV}$ was applied under control condition (black trace) and during $10 \mu \mathrm{M} \mathrm{Ca}^{2+}$ (blue trace). Digital subtraction (lower $\mathrm{Ca}^{2+}$ minus normal $\mathrm{Ca}^{2+}$ ) revealed the current normally inhibited by $\mathrm{Ca}^{2+}$ (red trace) and its $I-V$ relationship. The increased current by lowering $\mathrm{Ca}^{2+}$ also indicates a decreased input resistance or increased whole-cell conductance. $\boldsymbol{D}$, The $\mathrm{Ca}^{2+}$-sensitive current in $C$ displayed at higher magnification. The $I-V$ relationship is clearly linear between the entire voltage range of -90 to $0 \mathrm{mV}$ with no signs of voltage-dependent activation or inactivation and reversed its polarity around $-37 \mathrm{mV}$ on average (linear regression analysis as indicated by the black straight line, $r=0.998$ ).

tamate receptors, although activity of these channels is voltagedependent (Babich et al., 2007; Wang et al., 2007).

To further confirm our conclusion on TRPC3 channels, we used an antibody against the intracellular carboxyl terminal of TRPC3 channel protein (Alomone Labs). This antibody has been demonstrated to inhibit TRPC3 channels in smooth muscle cells and hippocampal neurons (Albert et al., 2006; Amaral and Pozzo-Miller, 2007). We added this antibody (at 1:100 dilution) to the intracellular pipette solution. The antibody should gradually diffuse into the recorded cells, bind to TRC3 channels, and interfere with their opening or gating, leading to decreased tonic whole-cell current (Albert et al., 2006). Consequently, the intracellularly perfused SNr GABA neurons may become hyperpolarized and the effect of FFA should be at least partially occluded or diminished.

Indeed, SNr GABA neurons intracellularly perfused with TRPC3 antibody became gradually hyperpolarized, reaching a steady-state resting potential of $-58.2 \pm 1.4 \mathrm{mV}(n=7)$ (Fig. $8 \mathrm{~A}$, Table 1) (for immunohistochemical evidence of effective antibody infusion, see supplemental Fig. 3, available at www. jneurosci.org as supplemental material). This was $\sim 8 \mathrm{mV}$ more hyperpolarized than under control condition, indicating that the tonic depolarization was reduced by $8 \mathrm{mV}$ by the TRPC 3 antibody. Furthermore, after intracellular perfusion of TRPC3 antibody, bath application of $100 \mu \mathrm{M}$ FFA induced a hyperpolarization of only $1.5 \pm 0.3 \mathrm{mV}$, much smaller than the nearly $10 \mathrm{mV}$ hyperpolarization induced under control condition $(p<0.001$, one-way ANOVA; $n=7$ ) (Table 1 ).

In contrast, when the SNr GABA neurons were perfused with TRPC3 antibody together with the antigenic peptide that should neutralize the antibody, the steady-state resting potential was $-49.8 \pm 1.2 \mathrm{mV}$ and bath application of $100 \mu \mathrm{M}$ FFA induced a
A Current clamp: intracellular application of TRPC3 antibody

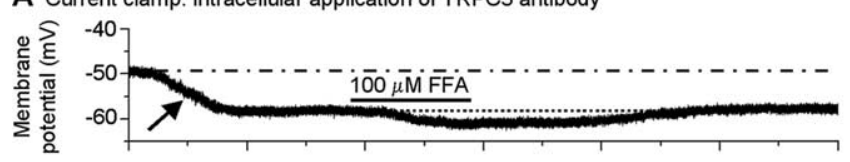

B Current clamp: Intracellular co-application of TRPC3 antibody and peptide

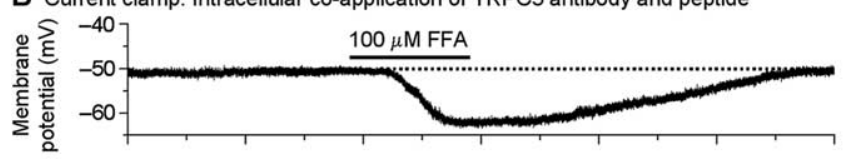

C Voltage clamp: Intracellular application of TRPC3 antibody

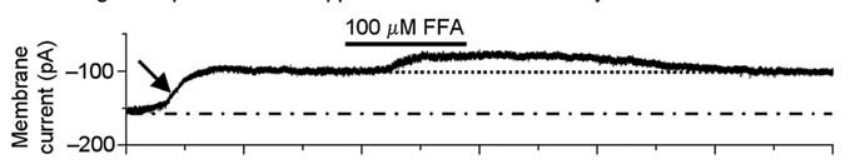

D Voltage clamp: intracellular co-application of TRPC3 antibody and peptide

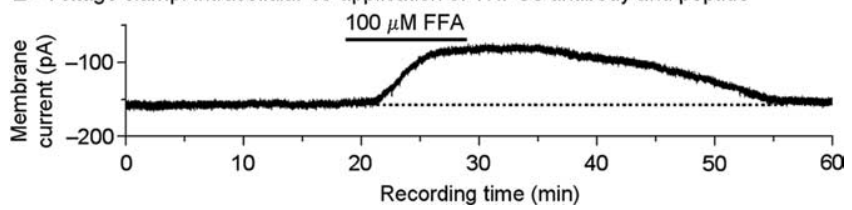

Figure 8. Intracellular application of TRPC3 antibody inhibits the depolarization and tonic inward current in SNr GABA neurons. $\boldsymbol{A}$, Under current-clamp recording mode and in the presence of $1 \mu \mathrm{M}$ TTX, the SNr GABA neurons became gradually more hyperpolarized when the intracellular pipette solution contained TRPC3 antibody diluted at 1:100. The effect reached a steady-state, leading to a new stable membrane potential around $-58 \mathrm{mV}$ on average. Note that the resting potential was around $-50 \mathrm{mV}$ with normal intracellular solution. Furthermore, bath application of $100 \mu \mathrm{m}$ FFA induced a hyperpolarization of only $\sim 1.5 \mathrm{mV}$, much smaller than the near $10 \mathrm{mV}$ hyperpolarization obtained with normal intracellular solution. $\boldsymbol{B}$, Under current-clamp recording mode and in the presence of $1 \mu \mathrm{M}$ TTX, when the SNr GABA neurons were intracellularly perfused with TRPC3 antibody together with the antigenic peptide that should neutralize the antibody, the resting membrane potential was not altered, remaining around $-50 \mathrm{mV}$. Bath application of $100 \mu \mathrm{m}$ FFA induced a hyperpolarization of $\sim 10 \mathrm{mV}$, similar to that obtained with normal intracellular solution. $C$, When voltage clamped at -70 $\mathrm{mV}$ and in the presence of $1 \mu \mathrm{m}$ TTX, intracellular perfusion of TRPC3 antibody gradually decreased the holding current with the steady-state holding current reaching around $-95 \mathrm{pA}$. Under this condition, bath application of $100 \mu \mathrm{m}$ FFA induced an outward current of only $\sim 11$ pA. $D$, When the cell was intracellularly perfused with both TRPC3 antibody and the antigenic peptide, the holding current was not altered, remaining around $-155 \mathrm{pA}$. Bath application of $100 \mu \mathrm{m}$ FFA induced an outward current of $\sim 70 \mathrm{pA}$, similar to those obtained with normal intracellular solution.

hyperpolarization of $9.5 \pm 1.1 \mathrm{mV}$, similar to these obtained with normal intracellular solution ( $p=0.892$, one-way ANOVA; $n=$ 5) (Fig. $8 B$, Table 1). These results indicate that the effects of TRPC3 antibody were specific.

When the SNr GABA neuron was voltage clamped at $-70 \mathrm{mV}$, intracellular perfusion of TRPC3 antibody gradually decreased the holding current to $-95.1 \pm 10.4 \mathrm{pA}(n=6)$ (Fig. $8 C)$, indicating the tonic inward current was reduced by $\sim 60 \mathrm{pA}$ by the intracellularly applied TRPC3 antibody. Under this condition, bath application of $100 \mu \mathrm{M}$ FFA induced an outward current of only $11.8 \pm 0.7 \mathrm{pA}(p<0.001$, one-way ANOVA; $n=6)$ (Fig. $8 C$, Table 1). In contrast, when the cells were intracellularly perfused with both TRPC3 antibody and the antigenic peptide, the steadystate holding current was $-155.4 \pm 11.7 \mathrm{pA}$ and bath application of $100 \mu \mathrm{M}$ FFA induced an outward current of $67.2 \pm 5.6 \mathrm{pA}$, similar to those obtained with normal intracellular solution ( $p=$ 0.677, one-way ANOVA; $n=5$ ) (Fig. 8D, Table 1).

These results clearly indicate that the TRPC3 antibody can selectively diminish the tonic inward current, providing conclu- 
sive evidence that it is the TRPC3 channel that normally mediates the tonic inward current in SNr GABA neurons that helps depolarize these neurons to action potential threshold.

\section{TRP channel blockade decrease the} frequency and increases the irregularity of SNr GABA neuron spiking

Our data presented above clearly demonstrate that $\mathrm{SNr}$ GABA neurons have a TRPC3 channel-mediated, constitutively active, linear inward current in the voltage range from $-90 \mathrm{mV}$ to around $-35 \mathrm{mV}$ that is the reversal potential of this tonic current and also $\sim 5 \mathrm{mV}$ more positive than the action potential threshold around $-40 \mathrm{mV}$ for SNr GABA neurons. The next question is: what functional roles do these TRPC3 channels play in SNr GABA neurons? We hypothesized that TRPC3 channels help depolarize SNr GABA neurons toward their action potential threshold around -40 $\mathrm{mV}$. Thus, we predicted that inhibition of TRPC3-mediated inward current will hyperpolarize the SNr GABA neurons such that the membrane potential of these neurons will not reach action potential threshold readily and reliably. Consequently, these neurons will not be able to fire action potentials regularly, leading to reduced firing frequency and increased firing irregularity.

Indeed, under current-clamp recording conditions, relatively low concentrations of FFA altered the firing rate and pattern in SNr GABA neurons. Bath application of $40 \mu \mathrm{M}$ FFA significantly increased interspike interval (ISI) from $102.9 \pm 4.2 \mathrm{~ms}$ under control to $328.0 \pm 46.3$ ms under FFA $(n=8 ; p<0.01)$ (Fig. $9 A, B)$. To quantify firing irregularity, the coefficient of variation $(\mathrm{CV})$ of the ISI, defined as the ratio of the SD of ISI over the mean ISI, was used (Bennett and Wilson, 1999; Lee et al., 2007). As shown in Figure 9C, under normal conditions, SNr GABA neurons fired spontaneously in a relatively regular manner with a narrow ISI distribution. During $40 \mu \mathrm{M}$ FFA bath application, however, these same SNr GABA neurons fired spontaneous spikes much more irregularly with wider ISI distribution. The CV of ISI increased from $0.11 \pm 0.02$ in control to $0.49 \pm 0.07$ under $40 \mu \mathrm{M}$ FFA $(n=8 ; p<0.01)$ (Fig. $9 C, D)$. High-concentration FFA $(100 \mu \mathrm{M})$ strongly hyperpolarized the recorded SNr GABA neurons such that these neurons often completely ceased to fire action potentials (Fig. 9E).

As expected, $40 \mu \mathrm{M} \mathrm{GdCl}_{3}$ also increased the ISI from $101.5 \pm$ $4.7 \mathrm{~ms}$ under control to $277.3 \pm 28.5 \mathrm{~ms}$ under $\mathrm{Gd}^{3+}(n=6)$ and increased CV of ISI from $0.12 \pm 0.03$ in control to $0.41 \pm 0.05$ $(n=6)$ in SNr GABA neurons. More important, intracellular application of TRPC3 antibody in SNr GABA neurons also substantially reduced the firing frequency, eventually leading to a complete cessation of spike firing (Table 1, Fig. 10). In contrast, intracellular coapplication of TRPC3 antibody and the antigenic peptide did not significantly affect the firing in these neurons (Table 1), indicating that the effects of TRPC3 antibody were specific. These results further support our idea that the TRPC3 channel-mediated tonic inward current helps the SNr GABA neuron fire rapid and regular spikes.
B FFA $(40 \mu \mathrm{M})$

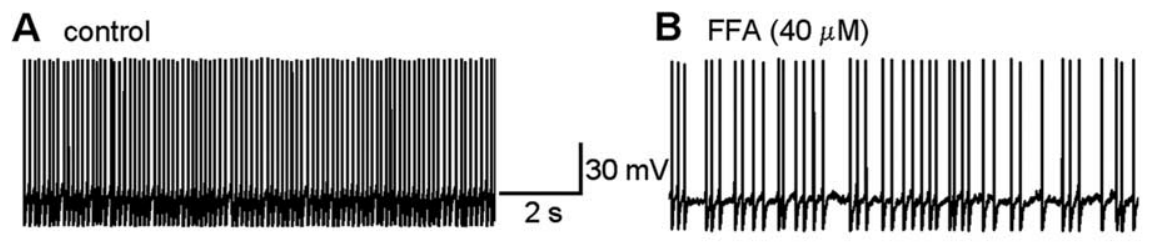

D $\operatorname{FFA}(40 \mu \mathrm{M})$

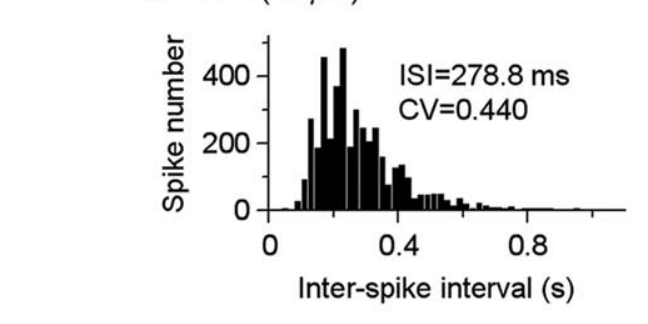

Inter-spike interval (s)

$|\mathrm{S}|=106.3 \mathrm{~ms}$ $\mathrm{CV}=0.116$

0.8

(s)
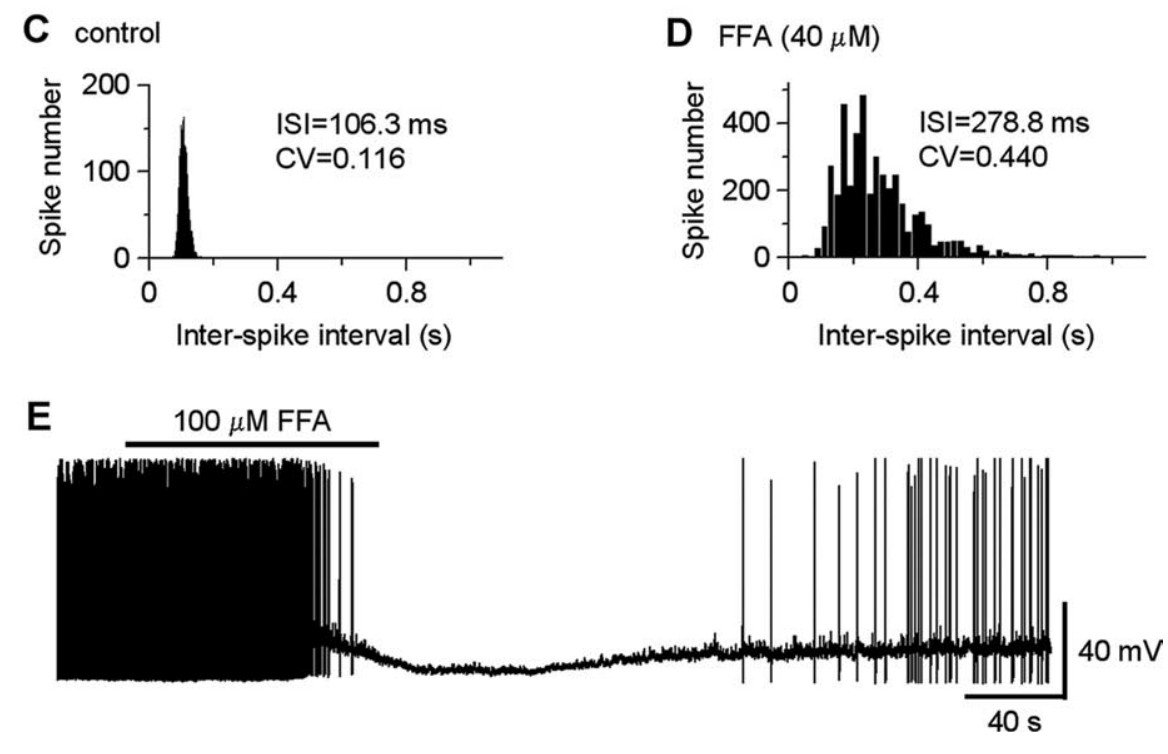
$0 \mathrm{mV}$

Figure 9. TRP channel blockade decreases the frequency and increases the irregularity of SNrGABA neuron spiking. $A$, Example cording of the spontaneous, relatively regular and high-frequency firing of an SNr GABA neuron under control condition. No . narrow under control condition. D, ISI distribution was wider and more irregular during bath application of $40 \mu \mathrm{m}$ FFA. E, An example continuous recording showing that $100 \mu \mathrm{m} F \mathrm{FA}$ induced a substantial hyperpolarization, leading to a complete cessation of spontaneous firing in SNr GABA neurons. Spike amplitude is distorted because of a $2 \mathrm{kHz}$ resampling for display.

\section{Discussion}

The main finding from our combined molecular, immunohistochemical, biophysical, and pharmacological experiments is that SNr GABA projection neurons selectively express TRPC3 channels that mediate a constitutively active inward current. This inward current provides a robust depolarization of around $10 \mathrm{mV}$ in these basal ganglia output neurons, leading to depolarized resting membrane potential and consequently reliable action potential firing.

\section{SNr GABA projection neurons selectively express} constitutively active TRPC 3 channels that mediate a tonic inward current and depolarization

Our single cell RT-PCR experiments consistently and reliably detected TRPC3 channel mRNA in SNr GABA neurons. mRNAs for the 27 other TRP channels were undetectable in these neurons. The possibility of false negative detection is minimal or unlikely because all of the primer pairs were proven to be effective with whole brain mRNAs. The translation of TRPC3 mRNA was confirmed by TRPC3 channel protein immunostaining in $\mathrm{SNr}$ GABA neurons. Therefore, we conclude that SNr GABA projection neurons selectively express TRPC3 channels. As will be discussed below, this selective expression matches perfectly the biophysical properties of the TRPC3 channel with the functional needs of the SNr GABA projection neuron.

Our patch clamp and pharmacological experiments show that SNr GABA neurons have a constitutively active, TTX-insensitive, $\mathrm{Na}^{+}$-dependent, voltage-independent linear inward current with a reversal potential around $-36 \mathrm{mV}$. This tonic inward current 


\section{A start TRPC3 antibody: fast and regular spiking}

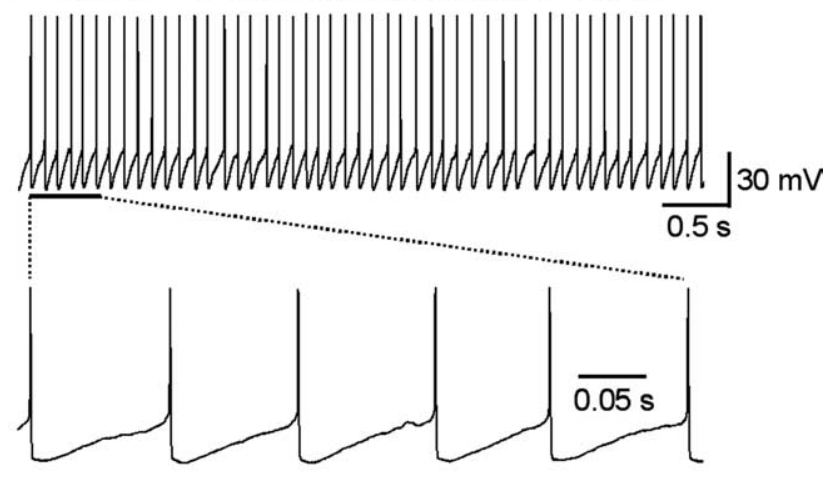

B 5 min later: slow and irregular spiking

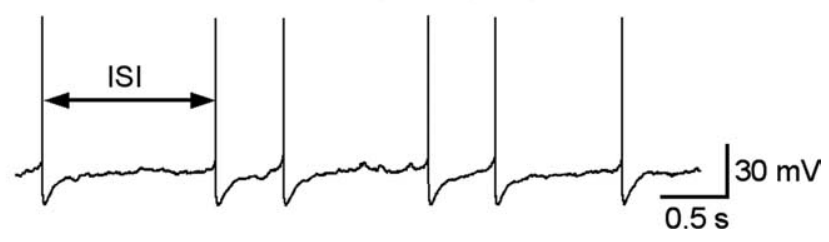

Figure 10. Intracellular application of TRPC3 antibody decreases the firing rate and increases the firing irregularity in SNr GABA neurons. $\boldsymbol{A}$, Example segment of recording shortly after going whole-cell mode with a patch pipette containing TRPC3 antibody. Within the first minute of recording when the antibody was not likely to have diffused sufficiently into the cell, the firing was fast $(9.9 \pm 0.5 \mathrm{~Hz} ; n=5$ cells) and regular (CV of ISI, $0.12 \pm 0.02$ ), not different from those recorded with normal intracellular pipette solution. The first six spikes were expanded for easy comparison with the six spikes in $\boldsymbol{B}$. $\boldsymbol{B}$, During the fifth minute of recording when considerable amount of the antibody was likely to have diffused into the cell, the spontaneous firing became much slow $(0.9 \pm 0.2 \mathrm{~Hz}, n=5$ cells) and irregular (CV of ISI, $0.98 \pm$ 0.05).

was blocked by TRP channel blocker flufenamic acid, leading to hyperpolarization of $\mathrm{SNr} \mathrm{GABA}$ neurons. It was also inhibited by extracellular $\mathrm{Ca}^{2+}$ and $\mathrm{Gd}^{3+}$, also causing hyperpolarization. These biophysical and pharmacological characteristics are similar or identical to those of native TRPC 3 channels in other cell systems (Clapham, 2003; Thorneloe and Nelson, 2004; Petkov et al., 2005; Albert et al., 2006; Ramsey et al., 2006; Hardie, 2007; Venkatachalam and Montell, 2007).

More importantly, intracellular application of TRPC3 antibody induced a hyperpolarization or an outward current, and largely prevented or occluded the effect of flufenamic acid. In contrast, intracellular coapplication of TRPC 3 antibody and the antigenic peptide resulted in no change in membrane potential or current, indicating the effects of intracellular application of TRPC3 antibody were specific. These data suggest that the TRPC3 antibody was interfering with the gating or opening of constitutively active TRPC3 channels, consistent with recent studies on TRPC3 channels in smooth muscle cells where these channels cause a tonic depolarization and help trigger action potential firing (Thorneloe and Nelson, 2004; Petkov et al., 2005; Albert et al., 2006).

Together, our data from multiple approaches clearly show that TRPC3 channels mediate a $\mathrm{Na}^{+}$-dependent, flufenamic acid-, $\mathrm{Gd}^{3+}$-, and $\mathrm{Ca}^{2+}$-sensitive, tonic inward current that reverses polarity around $-36 \mathrm{mV}$, above the action potential threshold of SNr GABA neurons. These tonically active TRPC3 channels are ideally suited to constantly depolarize and drive these basal ganglia output neurons toward their action potential threshold. Because these channels are active and conduct large inward or depolarizing currents at hyperpolarized membrane potentials, they are particularly useful in depolarizing these neurons when other voltage-dependent depolarizing ion channels are not active. For example, the TTX-sensitive persistent $\mathrm{Na}^{+}$ channel starts to significantly contribute to the depolarization of SNr GABA neurons only when the membrane potential is about $-50 \mathrm{mV}$ or more positive (Atherton and Bevan, 2005).

\section{Functional importance of TRP channels in $\mathrm{SNr}$ GABA neurons}

A key function of the basal ganglia is to inhibit, via the inhibitory output of SNr and GPi GABA projection neurons, the thalamic nuclei, the superior colliculus, and other brainstem motor nuclei (Albin et al., 1989; Alexander and Crutcher, 1990; Hikosaka et al., 2000; DeLong and Wichmann, 2007; Hikosaka, 2007). The inhibitory output from SNr GABA projection neurons (and probably also GPi GABA projection neurons) is encoded in their firing frequency and pattern (Hikosaka and Wurtz, 1983; Nevet et al., 2004; Hikosaka, 2007). Therefore, the spiking properties (frequency and pattern) of SNr GABA projection neurons are critical to movement control. A combination of inhibition and disinhibition may allow desired appropriate movements while suppressing inappropriate, competing movements such that an animal or person can have smooth, well coordinated movements (Hikosaka et al., 2000; Gulley et al., 2002; Hikosaka, 2007). Parkinsonian movement disorders are often associated with abnormalities in SNr GABA neuron firing. Recordings in animal models of Parkinson's disease and Parkinson's disease patients indicate that the SNr GABA neuron output in parkinsonian brain is often altered in its intensity and/or pattern (Bergman et al., 1998; Obeso et al., 2000; Hutchison et al., 2004; Nevet et al., 2004). Further demonstrating the importance of $\mathrm{SNr}$ in motor control and Parkinson's disease, inactivation of $\mathrm{SNr}$ in a primate model of Parkinson's disease has been shown to ameliorate parkinsonian motor symptoms (Wichmann et al., 2001).

In conclusion, our data show that the SNr GABA projection neurons selectively express TRPC 3 channels that are tonically active and mediate a $\mathrm{Na}^{+}$-dependent, voltage-independent inward current, thus guaranteeing basal ganglia neurons with a substantial depolarizing current. Inhibition of these channels induces hyperpolarization, leading to decreased firing frequency and increased firing irregularity. Thus, TRPC 3 channels play critical roles in maintaining the depolarized membrane potential, high firing frequency, and firing regularity in these basal ganglia output neurons, consequently contributing to motor control.

\section{References}

Albert AP, Pucovský V, Prestwich SA, Large WA (2006) TRPC3 properties of a native constitutively active $\mathrm{Ca}^{2+}$-permeable cation channel in rabbit ear artery myocytes. J Physiol (Lond) 571:361-369.

Albin RL, Young AB, Penney JB (1989) The functional anatomy of basal ganglia disorders. Trends Neurosci 12:366-375.

Alexander GE, Crutcher MD (1990) Functional architecture of basal ganglia circuits: neural substrates of parallel processing. Trends Neurosci 13:266-271.

Amaral MD, Pozzo-Miller L (2007) TRPC3 channels are necessary for brain-derived neurotrophic factor to activate a nonselective cationic current and to induce dendritic spine formation. J Neurosci 27:5179-5189.

Atherton JF, Bevan MD (2005) Ionic mechanisms underlying autonomous action potential generation in the somata and dendrites of GABAergic substantia nigra pars reticulata neurons in vitro. J Neurosci 25:8272-8281.

Babich O, Reeves J, Shirokov R (2007) Block of CaV1.2 channels by Gd ${ }^{3+}$ reveals preopening transitions in the selectivity filter. J Gen Physiol 129:461-475. 
Bennett BD, Wilson CJ (1999) Spontaneous activity of neostriatal cholinergic interneurons in vitro. J Neurosci 19:5586-5596.

Bergman H, Feingold A, Nini A, Raz A, Slovin H, Abeles M, Vaadia E (1998) Physiological aspects of information processing in the basal ganglia of normal and parkinsonian primates. Trends Neurosci 21:32-38.

Cebrian C, Parent A, Prensa L (2005) Patterns of axonal branching of neurons of the substantia nigra pars reticulata and pars lateralis in the rat. J Comp Neurol 492:349-369.

Clapham DE (2003) TRP channels as cellular sensors. Nature 426:517-524.

DeLong MR (1990) Primate models of movement disorders of basal ganglia origin. Trends Neurosci 13:281-285.

DeLong MR, Wichmann T (2007) Circuits and circuit disorders of the basal ganglia. Arch Neurol 64:20-24.

Deniau JM, Mailly P, Maurice N, Charpier S (2007) The pars reticulata of the substantia nigra: a window to basal ganglia output. Prog Brain Res 160:151-172.

Gonzalez-Hernandez T, Rodriguez M (2000) Compartmental organization and chemical profile of dopaminergic and GABAergic neurons in the substantia nigra of the rat. J Comp Neurol 421:107-135.

Gulley JM, Kosobud AE, Rebec GV (2002) Behav-related modulation of substantia nigra pars reticulata neurons in rats performing a conditioned reinforcement task. Neuroscience 111:337-349.

Hardie RC (2007) TRP channels and lipids: from Drosophila to mammalian physiology. J Physiol (Lond) 578:9-24.

Hikosaka O (2007) GABAergic output of the basal ganglia. Prog Brain Res 160:209-226.

Hikosaka O, Wurtz RH (1983) Visual and oculomotor functions of monkey substantia nigra pars reticulata. I. Relation of visual and auditory responses to saccades. J Neurophysiol 49:1230-1253.

Hikosaka O, Takikawa Y, Kawagoe R (2000) Role of the basal ganglia in the control of purposive saccadic eye movements. Physiol Rev 80:953-978.

Hutchison WD, Dostrovsky JO, Walters JR, Courtemanche R, Boraud T, Goldberg J, Brown P (2004) Neuronal oscillations in the basal ganglia and movement disorders: evidence from whole animal and human recordings. J Neurosci 24:9240-9243.

Lee CR, Tepper JM (2007) A calcium-activated nonselective cation conductance underlies the plateau potential in rat substantia nigra GABAergic neurons. J Neurosci 27:6531-6541.

Lee JI, Verhagen Metman L, Ohara S, Dougherty PM, Kim JH, Lenz FA (2007) Internal pallidal neuronal activity during mild drug-related dyskinesias in Parkinson's disease: decreased firing rates and altered firing patterns. J Neurophysiol 97:2627-2641.

Liss B, Roeper J (2004) Correlating function and gene expression of individual basal ganglia neurons. Trends Neurosci 27:475-481.

Maurice N, Thierry AM, Glowinski J, Deniau JM (2003) Spontaneous and evoked activity of substantia nigra pars reticulata neurons during highfrequency stimulation of the subthalamic nucleus. J Neurosci 23:9929-9936.

McCormick DA (2004) Membrane properties and neurotransmitter actions. In: The synaptic organization of the brain (Shepherd GM, ed), pp 39-77. New York: Oxford UP.

Moran MM, Xu H, Clapham DE (2004) TRP ion channels in the nervous system. Curr Opin Neurobiol 14:362-369.

Nevet A, Morris G, Saban G, Fainstein N, Bergman H (2004) Discharge rate of substantia nigra pars reticulata neurons is reduced in nonparkinsonian monkeys with apomorphine-induced orofacial dyskinesia. J Neurophysiol 92:1973-1981.
Nilius B, Owsianik G, Voets T, Peters JA (2007) Transient receptor potential cation channels in disease. Physiol Rev 87:165-217.

Obeso JA, Rodriguez-Oroz MC, Rodriguez M, Lanciego JL, Artieda J, Gonzalo N, Olanow CW (2000) Pathophysiology of the basal ganglia in Parkinson's disease. Trends Neurosci 23:S8-S19.

Parent A, Sato F, Wu Y, Gauthier J, Levesque M, Parent M (2000) Organization of the basal ganglia: the importance of axonal collateralization. Trends Neurosci 23:S20-S27.

Petkov GV, Balemba OB, Nelson MT, Mawe GM (2005) Identification of a spontaneously active, $\mathrm{Na}^{+}$-permeable channel in guinea pig gallbladder smooth muscle. Am J Physiol Gastrointest Liver Physiol 289:G501-G507.

Rajakumar N, Elisevich K, Flumerfelt BA (1994) Parvalbumin-containing GABAergic neurons in the basal ganglia output system of the rat. J Comp Neurol 350:324-336.

Ramsey IS, Delling M, Clapham DE (2006) An introduction to TRP channels. Annu Rev Physiol 68:619-647.

Rivlin-Etzion M, Marmor O, Heimer G, Raz A, Nini A, Bergman H (2006) Basal ganglia oscillations and pathophysiology of movement disorders. Curr Opin Neurobiol 16:629-637.

Sato M, Hikosaka O (2002) Role of primate substantia nigra pars reticulata in reward-oriented saccadic eye movement. J Neurosci 22:2363-2373.

Schultz W (1986) Activity of pars reticulata neurons of monkey substantia nigra in relation to motor, sensory, and complex events. J Neurophysiol 55:660-677.

Surmeier DJ, Song WJ, Yan Z (1996) Coordinated expression of dopamine receptors in neostriatal medium spiny neurons. J Neurosci 16:6579-6591.

Sylvester JB, Mwanjewe J, Grover AK (2001) Transient receptor potential protein mRNA expression in rat substantia nigra. Neurosci Lett 300:83-86.

Tang JK, Moro E, Lozano AM, Lang AE, Hutchison WD, Mahant N, Dostrovsky JO (2005) Firing rates of pallidal neurons are similar in Huntington's and Parkinson's disease patients. Exp Brain Res 166:230-236.

Thorneloe KS, Nelson MT (2004) Properties of a tonically active, sodiumpermeable current in mouse urinary bladder smooth muscle. Am J Physiol Cell Physiol 286:C1246-C1257.

Venkatachalam K, Montell C (2007) TRP Channels. Annu Rev Biochem 76:387-417.

Wang D, Grillner S, Wallén P (2007) Effects of flufenamic acid on fictive locomotion, plateau potentials, calcium channels and NMDA receptors in the lamprey spinal cord. Neuropharmacology 51:1038-1046.

Wichmann T, Soares J (2006) Neuronal firing before and after burst discharges in the monkey basal ganglia is predictably patterned in the normal state and altered in parkinsonism. J Neurophysiol 95:2120-2133.

Wichmann T, Bergman H, Starr PA, Subramanian T, Watts RL, DeLong MR (1999) Comparison of MPTP-induced changes in spontaneous neuronal discharge in the internal pallidal segment and in the substantia nigra pars reticulata in primates. Exp Brain Res 125:397-409.

Wichmann T, Kliem MA, DeLong MR (2001) Antiparkinsonian and behavioral effects of inactivation of the substantia nigra pars reticulata in hemiparkinsonian primates. Exp Neurol 167:410-424.

Zhou FW, Xu JJ, Zhao Y, LeDoux MS, Zhou FM (2006) Opposite functions of histamine $\mathrm{H}_{1}$ and $\mathrm{H}_{2}$ receptors and $\mathrm{H}_{3}$ receptor in substantia nigra pars reticulata. J Neurophysiol 96:1581-1591. 